\title{
Application Analysis of Mixed Learning in the Daily Teaching of Colleges and Universities
}

\author{
Yong $\mathrm{Xie}^{1, \mathrm{a}}$ \\ ${ }^{1}$ Xi'an International University, Shaanxi, Xi'an, China, 710077
}

Keywords: Application Analysis, Mixed Learning, Daily Teaching, Colleges and Universities

\begin{abstract}
At present, in the process of rapid social development in our country, the development of colleges and universities and the way of education have become a hot topic in the society at present. In the stage of rapid development of foreign language education, the reform of foreign language education has also become the focus of the current work of colleges and universities, mainly because the traditional way of education is not suitable for the development of students, so this paper proposes a mixed education model. And taking the English major as an example to understand the use of this teaching method in the daily teaching of colleges and universities, so as to provide the latest development path for the teaching reform of the campus and promote the development and progress of the students.
\end{abstract}

\section{Introduction}

At present, in the social development stage, the situation of college education began to be concerned about, mainly because people in the increasingly material life, the ideological also has some reform, so more and more people think that good education, for the future development of students, as well as the continuous progress of society has a very important role in promoting. In the following article, this paper analyzes the application of the mixed teaching model in the daily teaching of colleges and universities, and takes the foreign language specialty as an example to focus on the development of this teaching method, so as to better promote the development and progress of the students.

\section{The Concept of Mixed Learning}

The Definition of Mixed Teaching. In fact, the mixed teaching model, in the name can be seen on a variety of teaching and learning methods of the mix, the advantages of all teaching models to explore, and in all teaching advantages, find the fit point, in order to integrate, the better to promote the development of campus teaching, such as: the teaching model, the classroom teaching and extracurricular teaching methods can be combined; also able to combine media teaching and blackboard teaching; also able to computer-assisted teaching and traditional teaching combination; and the combination of autonomous learning and writing learning. It can be seen that the mixed teaching method is the integration between the various teaching modes, to maximize the lessons learned in the teaching model, the teaching effect to the highest. But in fact, the mixed teaching model is not only the mix of elements between teaching, nor is it a simple teaching means of superposition, but between the various elements of the mutual cooperation and integration, this teaching model can be in the entire teaching of all links reflected, to ensure that students can in different ways, to receive better, more knowledge content [1].

The Principle of Mixed Teaching. In the traditional campus teaching process, almost all of our teachers are using the teacher as the classroom center of the teaching model, but at this stage, this method has been fully proved, is not an ideal teaching method, mainly because of a lot of professional and disciplinary knowledge content, is not the need to simply give the student theoretical content, but also need to give students more applications and practices, including college English teaching is one of the more typical of a subject, mainly because of foreign language the teaching of the course is not only the need for students to master the language and the relevant knowledge content, but also need to exercise and develop students the ability to use language. And 
this ability, not the teacher can teach the students. Therefore, in the foreign language classroom also need to cultivate students' interest in learning, and through the activities of the classroom, as well as the entire teaching requirements, to create a true and effective method for students to learn. And the mixed teaching model just met the content requirements, fundamentally overcome the traditional classroom teaching and modern network teaching deficiencies, the classroom teacher-led and online learning students in the main model of the mix, which is in the classroom traditional teaching and online teaching on the basis of the development of a new teaching methods, and this teaching method is also fundamentally began to reform the campus teachers and students in the learning relationship between [2].

In colleges and universities, the use of mixed teaching model, not only on the basis of the various subjects to improve the teaching level of teachers, as well as the ability of professional knowledge of scientific research, but also can effectively change the way students in the learning process, Improve the students' interest in learning and hobbies, which can also improve the overall quality and ability of students to ensure that students in the future social crystal dominance, but also fundamentally promote the reform of the campus teaching to improve the quality of teaching [3].

\section{The Traditional University Daily Teaching Mode - Taking English Majors as an Example}

While communication between our country and the western countries is increasing, foreign language education has also become a very important content in various colleges and universities, mainly because the development and progress of society depends on young people, and the knowledge of young people is related to the future of society to the direction. So the colleges and universities gradually began to explore the latest mode of foreign language teaching model, the main purpose is to ensure classroom efficiency at the same time, to find the best way to teach, in order to better stimulate students' enthusiasm for learning. In the traditional colleges and universities, for the English professional can see that its teaching methods have great drawbacks, because the professional students in the future work requires a lot of use of English, so the traditional teaching, the teacher is blindly to the students grammar, words, sentence, etc., the purpose is to let students through their own teaching to master the way people communicate and communicate with the way, and the greatest degree of knowledge to students about the content of English. After the completion of such a classroom in the university, the teacher will be very tired, but the students did not learn more knowledge, mainly the whole classroom is the teacher-led, the students need to learn the content of knowledge to instill students, but so students are completely Passive state, many students do not even know what the teacher is saying, which also largely cause the classroom ineffective situation [4].

\section{The Design of the Mixed Teaching Mode in the Daily Teaching of Colleges and Universities - Taking English Majors as an Example}

Colleges and Universities English Daily Teaching Environment in the Mixed Mode. In order to ensure that the mixed teaching model in the English professional to carry out smoothly, the campus also need to ensure that the classroom required hardware facilities and software facilities environment, including hardware facilities mainly in the modern information technology under the guidance of the teaching environment. There are teachers and students in the classroom to carry out the process of language classroom or multimedia classroom, so in the classroom also need to be equipped with a variety of teaching equipment, including computers, projectors, blackboard, mobile tables and chairs. The software is worthy of the entire teaching environment in the soft environment, mainly teachers and students to use the transmission of knowledge and teaching content of the network, as well as virtual teaching software and so on. But also between teachers and students to communicate between the forum, paste it, chat rooms, etc., in such a platform, teachers and students can better contact and exchange, in order to find the problems in teaching, which is a mixed teaching methods, to the traditional suppression of classroom and teacher-student communication methods in order to promote the progress of students [5]. 
Colleges and Universities English Teaching Resources in Mixed Mode. In college English majors, the use of teaching resources is generally to ensure that students can complete the learning process throughout the learning process, which is a prerequisite for the use of teaching resources. The mixed teaching mode, in this teaching case, the integration of a variety of learning methods, in addition to enrich the teaching resources, but also the traditional classroom paper textbooks, teacher lesson plans and network courses, teaching courseware and the Q \& A library and so on, so that students can learn through the traditional teaching materials, and the teacher's teaching ideas also have the order, but also can use the extracurricular software for classroom knowledge expansion, in order to broaden the students' English field of vision, more good to promote the development and progress of students [6].

Colleges and Universities English Teaching Methods in the Mixed Mode. In the mixed teaching mode, the first need to highlight is the dominant position of teachers, but also need to highlight the nature of the students, because the traditional teaching is a teacher and students a single person as the main body, which will be to a large extent affect the teaching effect of the entire classroom, and mixed teaching is to highlight the two, and better teachers and students between the main location of the integration and show. The second is the need to mix the traditional classroom teaching model and network teaching mode, so that students can learn more knowledge in the latest model, which can also stimulate students' enthusiasm for learning English, change the traditional full culture, happening. It is necessary to combine students' autonomous learning and cooperative learning. Because of the reform of college English curriculum under the new curriculum reform mode, many teachers have reformed them for reform and applied the cooperative teaching method in the classroom, which also led to the long-term development of students after no topic can be discussed, even in the group when learning, are chatting each other, it is difficult to highlight the teaching effect. Mixed teaching mode is to combine autonomy and cooperation, the teacher needs to start in the course of the early, analysis of course content, whether the need to discuss, if necessary, grouped, or follow the traditional teaching model, so that students learn their own, so that students can bring Freshness at the same time, but also to better promote the progress of students.

Colleges and Universities English Teaching Evaluation in Mixed Mode. As a long time since our country's education work is in accordance with the traditional way of development, so many teachers on the campus because of relatively senior qualifications, teaching practice is relatively long, so fixed thinking mode is difficult to change, and even many teachers that the traditional teaching model has its own advantages, do not accept the latest online teaching model. This is also a certain extent for the development of university education work obstacles. In the course of traditional college English classroom development, teachers' evaluation of student achievement and learning effect is generally in the form of final examinations. The results of this examination account for about $70 \%$ of the total evaluation, the normal classroom performance, and the daily examination results accounting for about $30 \%$. This evaluation model to a large extent restricted the free development of students, many students in the beginning of the study in order to test the continuous review and learning, completely confined to the test content, the teacher's teaching is also based on the examination, a large part of this student in the future work of the community are difficult to play their own ability, and even still affected by the classroom and the campus. Therefore, the mixed teaching model allows effective classroom evaluation and traditional test evaluation combined with each other, the teacher uses a variety of evaluation methods to sum up the students' learning situation, which can effectively reduce the students due to test stress caused by a single learning model to promote the development and progress of students.

\section{Conclusion}

At the present stage, with the continuous development and progress of our society, more and more people pay attention to the importance of campus education in daily life and work, mainly because of the good education work can make students learn theoretical knowledge well at the same time, the overall quality has also been improved, so it has a good role in promoting the future 
development of society. However, this teaching model also has some problems, the hybrid teaching model completely make up for the defects of this teaching content. This teaching method is mainly mixing the traditional teaching and the latest teaching methods in order to ensure maximize the advantages of education work, which can also form a good learning and education work to ensure that students' progress at the same time, the teacher's teaching ability and level has also been improved.

\section{References}

[1] Li Le, Yao Xincheng, Tang Hui. The application of mixed teaching in college classroom taking drug analysis as an example[J]. Health Vocational Education, 2017, (03): 59-60.

[2] Zhang Lijun. Based on the mixed learning model of university computer application basic course teaching reform[J]. China Management Information, 2016, (16): 235-236.

[3] Shi Yun, Chen Wei, Guan Yanyun. Application of Learning Analysis Technology and Computer Adaptive Test in Moodle's Mixed Teaching [J]. Education and Teaching Forum, 2016, (24): 212-213.

[4] He Fugen. Implicit learning theory in college volleyball elective course teaching application analysis[J]. Contemporary sports science and technology, 2016, (04): 67-68.

[5] Song Xiaoxing. Study on the Application of Mixed Learning Model Based on Micro-class in College English Teaching in Adult Colleges [J] .Journal of Xuanwu Hongqi Amateur University, 2016, (02): 50-52 + 60 .

[6] Zhang Shenghua, Zou Guohui.Application and practice of mixed learning in "non-linear editing" course [J]. Education and Teaching Forum, 2015, (36): 152-155. 